\title{
Operative repair of iatrogenic innominate artery to left innominate vein arteriovenous fistula after pacemaker laser lead extraction
}

Peter C. Chen, MD, ${ }^{\mathrm{a}}$ Scott Greenberg, MD, ${ }^{\mathrm{b}}$ Nilesh Mathuria, MD, ${ }^{\mathrm{b}}$ and James J. Livesay, MD, ${ }^{\mathrm{a}}$ Houston, Tex

From the Departments of a Cardiovascular Surgery and ${ }^{\mathrm{b}}$ Adult Cardiology, Texas Heart Institute at St Luke's Episcopal Hospital, Houston, Tex.

Disclosures: Authors have nothing to disclose with regard to commercial support.

Received for publication March 25, 2016; revisions received May 30, 2016; accepted for publication May 31, 2016; available ahead of print July 9, 2016.

Address for reprints: Peter C. Chen, MD, Department of Cardiovascular Surgery, Texas Heart Institute at St

Luke's Episcopal Hospital, 6770 Bertner Ave, Houston, TX 77030 (E-mail: peter.chen@bcm.edu).

J Thorac Cardiovasc Surg 2016;152:e85-7

$0022-5223 / \$ 36.00$

Copyright (c) 2016 by The American Association for Thoracic Surgery

http://dx.doi.org/10.1016/j.jtcvs.2016.05.062

Percutaneous extraction methods of pacemaker and defibrillator leads have decreased morbidity in comparison with open chest surgery, but carry the risk for potential iatrogenic cardiovascular injury. We report a rare case of multiple iatrogenic arteriovenous fistulae (AVF) after laser lead extraction with resulting right-sided heart failure and tricuspid regurgitation (TR) requiring percutaneous and surgical closure of the fistulae, and placement of a tricuspid annuloplasty ring.

\section{CLINICAL SUMMARY}

A 37-year-old woman with congenital atrioventricular heart block underwent a pulse generator exchange with laser lead extraction of a dislodged right atrial lead. The original pacemaker was placed 20 years prior, and the patient had undergone multiple prior revisions. Access was obtained through the left axillary vein, and using a locking stylet with $14 \mathrm{~F}$ and $16 \mathrm{~F}$ sheaths, laser extraction of the right atrial lead was attempted, but was unsuccessful due to significant calcification and bleeding at the entry site. The patient was

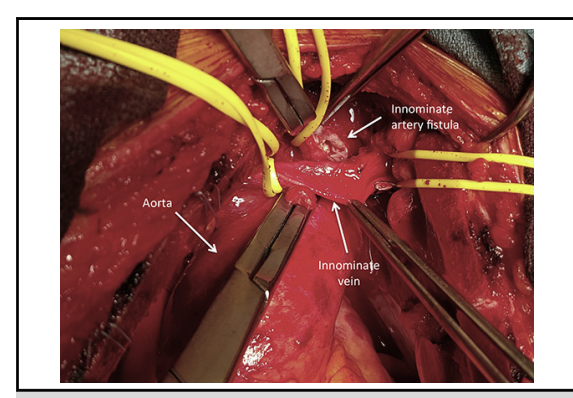

latrogenic fistula between the innominate artery and left innominate vein.

Central Message

Iatrogenic arteriovenous fistula after laser lead extraction is a potentially serious complication that requires prompt diagnosis and intervention.

See Editorial Commentary page e89.

discharged home; however, she returned with worsening dyspnea and a new, continuous murmur on physical exam. Echocardiography findings were consistent with right ventricular volume overload and arteriography demonstrated a left internal thoracic artery to left subclavian vein fistula. The patient underwent successful left internal thoracic artery stenting. Several weeks later, the patient returned with recurrent symptoms and findings on echocardiography demonstrating persistent right heart enlargement with new

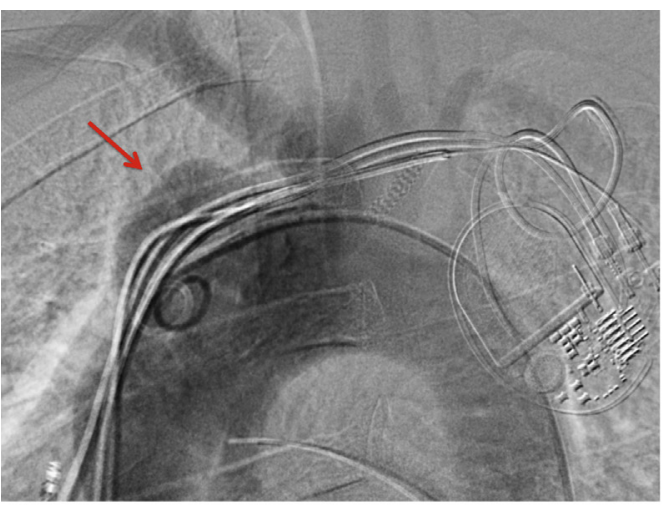

A

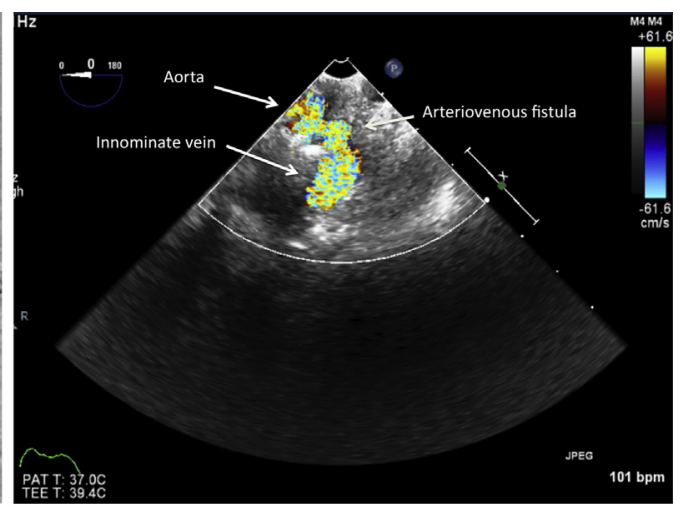

B

FIGURE 1. A, Angiography demonstrating saccular outpouching of ascending aorta or proximal innominate artery (red arrow). B, Echocardiography image demonstrating abnormal communication between the distal ascending aorta and left innominate vein. 

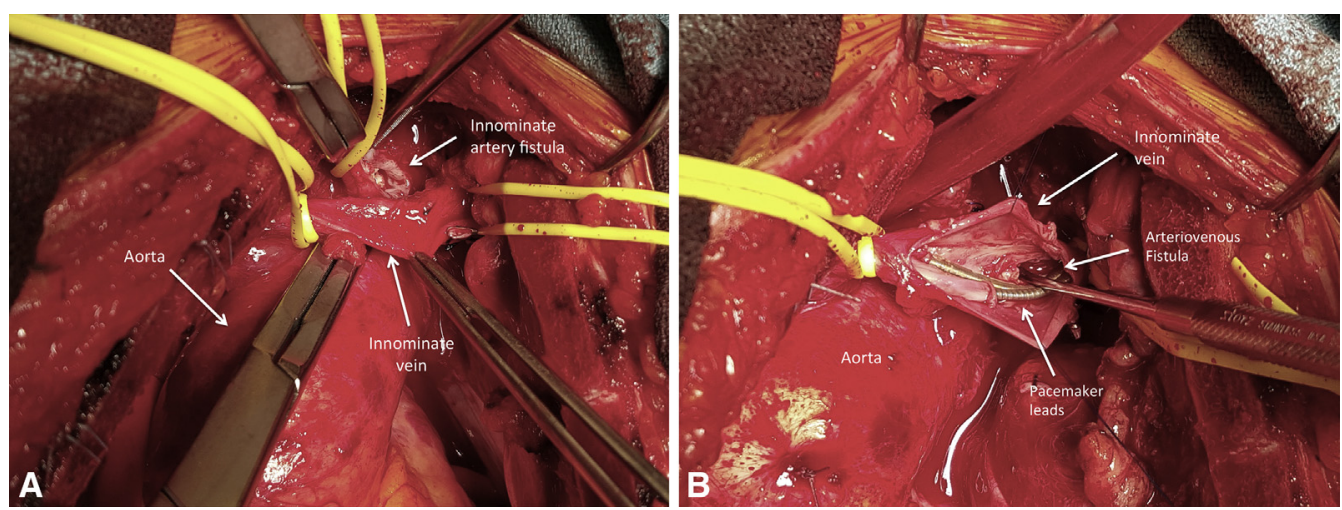

FIGURE 2. A, Intraoperative photograph showing 1-cm innominate artery fistula opening. B, Intraoperative photograph showing venotomy on the anterior surface of the left innominate vein exposing a $1-\mathrm{cm}$ posterior fistula opening.

moderate-severe TR and concern for a flail anterior leaflet due to chordal rupture (Figure 1, B). Systolic pulmonary artery pressures increased from 25 to $55 \mathrm{~mm} \mathrm{Hg}$. Computed tomography angiogram and repeat arteriography demonstrated continuous flow in the innominate artery and distal ascending aorta concerning for pseudoaneurysm and AVF (Figure 1, A). The patient was taken to the operating room for AVF ligation and tricuspid valve (TV) repair.

\section{SURGICAL TECHNIQUE}

A median sternotomy was performed, the femoral vessels were cannulated, and cardiopulmonary bypass was initiated. The left innominate vein was dissected free from dense scar tissue. A pseudoaneurysm of approximately $1 \mathrm{~cm}$ was identified between the anterior surface of the proximal innominate artery and the posterior surface of the left innominate vein (Figure 2). The fistulous openings in the artery and vein measured approximately $1 \mathrm{~cm}$ in diameter. Vascular control of both artery and vein was obtained, and the fistula was opened. Cerebral near-infrared spectroscopy was monitored during snaring of the innominate artery with no change from baseline values. The opening on the anterior innominate artery was closed primarily with prolene sutures. We incised the anterior surface of

TABLE 1. Literature review of iatrogenic arteriovenous fistula after laser lead extraction

\begin{tabular}{|c|c|c|c|c|c|c|}
\hline Author & Year & $\begin{array}{l}\text { No. of } \\
\text { cases }\end{array}$ & Type & $\begin{array}{l}\text { Timing of } \\
\text { diagnosis }\end{array}$ & Procedure & Outcome \\
\hline Bracke and colleagues $^{2}$ & 1999 & 1 & LITA-LSCV & $0 \mathrm{~d}$ & Coil embolization & Discharge \\
\hline \multirow[t]{2}{*}{ Kumins and colleagues } & 2000 & 2 & BCA-LBCV & $0 \mathrm{~d}$ & No intervention & Mortality \\
\hline & & & LCCA-LBCV & $0 \mathrm{~d}$ & $\begin{array}{l}\text { Sternotomy, aorta-LCCA bypass, } \\
\text { fistula, and LCCA ligation }\end{array}$ & Discharge \\
\hline Milla and colleagues & 2006 & 1 & LCCA-LBCV & $14 \mathrm{~d}$ & $\begin{array}{l}\text { Sternotomy, aorta-LCCA bypass, } \\
\text { fistula, and LCCA ligation }\end{array}$ & Discharge \\
\hline \multirow[t]{2}{*}{ Lawton and colleagues } & 2006 & 2 & LCCA-LSCV & $5 \mathrm{~d}$ & No intervention & Mortality \\
\hline & & & LSCA-LSCV & $0 \mathrm{~d}$ & Stent & Discharge \\
\hline Alayadhi and colleagues & 2009 & 1 & LCCA-LSCV & Unknown & Stent & Discharge \\
\hline \multirow[t]{2}{*}{$\mathrm{O}^{\prime}$ Connor and colleagues ${ }^{5}$} & 2010 & 2 & LSCA-LSCV & $30 \mathrm{~d}$ & Stent & Discharge \\
\hline & & & LCCA-LBCV & & Stent & \\
\hline Strickman and colleagues & 2012 & 1 & RITA-SVC & $30 \mathrm{~d}$ & Stent & Discharge \\
\hline Anastacio and colleagues ${ }^{4}$ & 2012 & 1 & LITA-LSCV & $0 \mathrm{~d}$ & Coil embolization & Discharge \\
\hline Yamada and colleagues & 2013 & 1 & LITA-LBCV & $0 \mathrm{~d}$ & Stent & Discharge \\
\hline Hanninen and colleagues & 2013 & 1 & LITA-LBCV & $3 \mathrm{~d}$ & Stent & Discharge \\
\hline \multirow[t]{5}{*}{ Cronin and colleagues ${ }^{3}$} & 2014 & 8 total & & & & \\
\hline & & 3 & LITA-LSCV & $3-586 \mathrm{~d}$ & Stent (2), attempted coiling (1) & $\begin{array}{l}\text { Discharge (1), mortality } \\
\text { (2 at } 98 \text { and } 656 \mathrm{~d})\end{array}$ \\
\hline & & 1 & LSCA-LSCV & $13 \mathrm{~d}$ & Glue embolization & Discharge \\
\hline & & 3 & BCA-LBCV & $0 \mathrm{~d}$ & Stent (2), spontaneous closure (1) & $\begin{array}{l}\text { Mortality (1 at } 216 \mathrm{~d}) \\
\text { discharge (2) }\end{array}$ \\
\hline & & 1 & Aorta-LBCV & $0 \mathrm{~d}$ & No intervention & Mortality \\
\hline
\end{tabular}

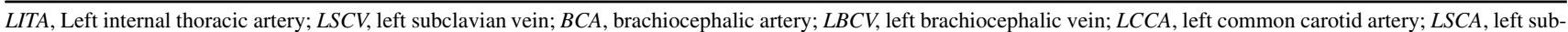
clavian artery; RITA, right internal thoracic artery; SVC, superior vena cava. 
the left innominate vein, providing access to the fistulous tract, which we primarily closed with prolene sutures. The calcified right atrial lead was removed and the left innominate vein was closed with a patch. The TV annulus was severely dilated and 1 pacemaker lead had torn through the anterior leaflet of the TV, explaining the preoperative echocardiogram findings. All chordae were intact. This injury appeared chronic because the lead was scarred into the leaflet and did not appear to affect valve function, and therefore no intervention took place. A 31-mm tricuspid annuloplasty ring was placed. Postoperative echocardiogram demonstrated successful fistula ligation and no TR.

\section{DISCUSSION}

Percutaneous extraction of pacemaker and defibrillator leads provides a safe method with decreased morbidity compared with open chest surgery. ${ }^{1}$ Although complications from laser lead extraction can be catastrophic, occasionally these complications are insidious with symptomatic presentation, including chest pain, progressive dyspnea, extremity edema, new murmur or thrill on physical exam, and radiographic abnormalities (eg, widened mediastinum). We identified 11 articles reporting the complication of iatrogenic AVF development after laser lead extraction since the first reported case in 1999 (Table 1). ${ }^{2}$ The largest series reported is by Cronin and colleagues, ${ }^{3}$ who identify 8 patients in their experience with an incidence of $0.3 \%$. The majority underwent successful endovascular stenting $(52 \%)$. Other interventions included operative intervention, coil embolization, or expectant management with spontaneous closure. ${ }^{4}$ There were 3 perioperative mortalities $(14 \%)$ in patients who died before intervention.
Our patient presented with delayed symptoms of right heart failure due to her left-to-right shunting. Initially, only 1 fistula was identified, allowing progression of her right heart failure and TR. We believed the safest option, with potential involvement of the aorta, was to surgically identify and repair her AVF during the period of cardiopulmonary bypass. Furthermore, repair of her TV was performed due to the severity of regurgitation at the time of fistula ligation.

\section{CONCLUSIONS}

Iatrogenic AVF after laser lead extraction is a potentially serious complication that requires prompt diagnosis and intervention. Angiography may be warranted in technically challenging lead extraction procedures with excessive blood loss to assess for iatrogenic AVF. Findings of a new, continuous murmur and right heart failure symptoms should prompt further investigation into this potentially lethal complication.

\section{References}

1. Moon MR, Camillo CJ, Gleva MJ. Laser-assist during extraction of chronically implanted pacemaker and defibrillator leads. Ann Thorac Surg. 2002;73:1893-6.

2. Bracke FA, van Gelder B, Meijer A. Arteriovenous fistula after injury of the lef internal mammary artery during extraction of pacemaker leads with a laser sheath. Pacing Clin Electrophysiol. 1999;22:833-4.

3. Cronin EM, Brunner MP, Tan CD, Rene Rodriguez E, Rickard J Martin DO, et al. Incidence, management, and outcomes of the arteriovenous fistula complicating transvenous lead extraction. Heart Rhythm. 2014;11:404-11.

4. Anastacio MM, Castillo-Sang M, Smith TW, Saad N, Lawton JS. Iatrogenic lef internal thoracic artery to left subclavian vein fistula after excimer laser pacemaker lead extraction. J Thorac Cardiovasc Surg. 2012;143:e35-7.

5. O'Connor DJ, Gross J, King B, Suggs WD, Gargiulo NJ 3rd, Lipsitz EC Endovascular management of multiple arteriovenous fistulae following failed laserassisted pacemaker lead extraction. J Vasc Surg. 2010;51:1517-20. 